\title{
The Terminologia Anatomica matters: examples from didactic, scientific, and clinical practice
}

\author{
B. Strzelec ${ }^{1,2}$, P.P. Chmielewski ${ }^{1}$, B. Gworys ${ }^{1}$ \\ ${ }^{1}$ Division of Anatomy, Department of Human Morphology and Embryology, Faculty of Medicine, \\ Wroclaw Medical University, Wroclaw, Poland \\ ${ }^{2}$ Department and Clinic of Gastrointestinal and General Surgery, Wroclaw Medical University, Wroclaw, Poland
}

[Received: 19 August 2016; Accepted: 20 October 2016]

\begin{abstract}
The proper usage of the anatomical terminology is of paramount importance to all medical professionals. Although a multitude of studies have been devoted to issues associated with the use and application of the recent version of the anatomical terminology in both theoretical medicine and clinical practice, there are still many unresolved problems such as confusing terms, inconsistencies, and errors, including grammar and spelling mistakes. The aim of this article is to describe the current situation of the anatomical terminology and its usage in practice, as well as explain why it is so important to use precise, appropriate, and valid anatomical terms during the everyday communication among physicians from all medical branches. In this review, we discuss some confusing, obsolete, and erroneous terms that are still commonly used by many clinicians, and surgeons in particular, during the process of diagnosis and treatment. The use of these ambiguous, erroneous, and obsolete terms enhances the risk of miscommunication. We also provide some edifying examples from everyday clinical practice. (Folia Morphol 2017; 76, 3: 340-347)
\end{abstract}

Key words: anatomical terminology, anatomical nomenclature, clinical anatomy, clinical practice, coding system of Terminologia Anatomica, general anatomy, gross anatomy

\section{INTRODUCTION}

Unlike in other medical fields, in anatomy it is important to distinguish between terminology, which is the set of terms approved by the Federative Committee on Anatomical Terminology (FCAT) and nomenclature, which is the standardised system of precisely defined terms, created within the scope of terminology $[6,10,12]$.

Human anatomy is a fundamental science, and the proper usage of anatomical terminology is of paramount importance to both medical students and practicing physicians $[9,18,28,29]$. Learning, remembering, and understanding the specialised anatomical terms are arguably the greatest challenges faced by first year medical students. All the more so because the ana- tomical vocabulary is based on Ancient Greek and Latin words, contains casual eponyms, used especially by clinicians and surgeons, and the literal meaning of a term may not lend insight into its definition. Moreover, the terminology commonly used by health care professionals in hospitals may significantly differ from the official terminology used by anatomists. Such discrepancy can be a source of confusion or erroneous diagnosis and treatment, which eventually can be pernicious. Therefore, the use of the recent version of the anatomical terminology [5] in clinical practice is highly recommended [10-13]. Although a host of studies have focused on issues associated with the use and application of anatomical terminology and nomenclature in prac-

Address for correspondence: Dr. P.P. Chmielewski, Division of Anatomy, Department of Human Morphology and Embryology, Faculty of Medicine, Wroclaw Medical University, ul. T. Chałubińskiego 6a, 50-368 Wrocław, Poland, e-mail: piotr.chmielewski@umed.wroc.pl 
tice $[9,13,14,17-22,27,30-32]$, there are still many unresolved problems. For example, there is currently no precise definition of fascia as a unit $[15,25,26]$. Similarly, we lack an exact definition of an arteriole [8]. Moreover, numerous terms are stated as synonyms [13]. It should be stressed, however, that any minor change to the current version of the anatomical terminology [5] should be introduced with utmost caution, and any major change would do more harm than good.

The purpose of this article is to describe the current situation of the anatomical terminology and its usage in clinical practice, as well as to explain why it is so important to use precise, appropriate, and valid anatomical terms during both the process of teaching anatomy to medical students and in the everyday communication among health care specialists from all medical branches. We discuss some confusing, obsolete, and erroneous terms that are still commonly used by clinicians and surgeons during diagnosis and treatment, which can easily lead to miscommunication and misunderstanding. We also provide some edifying examples from everyday didactic and clinical practice.

\section{THE HISTORICAL DEVELOPMENT OF THE ANATOMICAL TERMINOLOGY}

The anatomical terminology has been a matter of controversy and disagreement since time immemorial. The same anatomical structures were differently named, described, and defined by different authors. Many terms designated the shape, resemblance to other structures, or the function of the anatomical structures or even religious beliefs and misunderstandings like the issue of Adam's apple. Therefore, over the centuries, many attempts have been made in order to establish a general terminology that would be acceptable to all anatomists throughout the world.

Ancient authors like Galen used only a limited number of terms, and they were usually colloquial Greek words [23]. In the early $16^{\text {th }}$ century, Andreas Vesalius, one of the founders of modern human anatomy, described many new structures with the help of detailed and magnificent illustrations in his books. The third stage of development of terminology in the late $16^{\text {th }}$ century was marked by innovation of a large number of terms for the muscles, nerves, and blood vessels. Sylvius in Paris and Bauhin in Basel, were the most prominent figures at that stage of the development of anatomical terminology and nomenclature [23].

In 1895, an international commission formulated a standardised and simplified nomenclature, known as the Basel Nomina Anatomica (BNA), which omitted many synonymous and eponymous terms. In 1897, Professor Stanisław Krysiński incorporated the BNA into the Polish anatomical terminology. The BNA was accepted in Europe and in America, although older clinicians continued to use the previous terminology. Moreover, the BNA was not accepted worldwide, e.g. in France and Great Britain. In 1928, a Committee of the Anatomists of Great Britain and Ireland was set up. The committee adopted the nomenclature known as the Birmingham Revision (BR). In 1935, the Jena Nomina Anatomica (JNA) reformed the system of anatomical nomenclature, but this attempt received little attention. Until 1955, the BNA and JNA remained the standard international anatomical terminology. In 1955, the International Anatomical Nomenclature Committee (IANC) established the Nomina Anatomica (NA), which contained 5640 terms (4311 items), of which $76 \%$ were unchanged from the BNA [13].

\section{A CRITICAL ANALYSIS OF THE TERMINOLOGIA ANATOMICA}

In 1997, the latest revision of the Latin and English terminology was approved by the FCAT and published as Terminologia Anatomica (TA) in 1998 [5]. It contains 7635 items, which shows a trend of extension and stabilisation of nomenclature. Nevertheless, several errors, including typographical ones, as well as some inconsistencies have been noted. Therefore, a new edition of TA has been published online in 2011 along with several corrections and remedies to these errors. Moreover, it has emerged that the TA has several weak points, discrepancies, and certain segments are insufficiently rich as they do not contain new terms for some small or variant structures. Since these structures and appropriate terms for them are very important from a scientific point of view, some authors selected the most important structures and proposed new terms for them in order to ameliorate and extend the most recent version of the TA [14]. Modern anatomical terms used in TA designate:

- the shape of structures or resemblance to some other structures found in nature, e.g. arachnoidea mater, hippocampus, uncus, cochlea, cauda equina, sella turcica, cartilago arytenoidea et cricoidea, musculus deltoideus et trapezius, os pisiforme, vomer;

- the size or dimension of structures, e.g. tuberculum majus et minus (humeri), trochanter major et minor (femoris), musculus gluteus maximus, medius et minimus, $m$. latissimus dorsi, $m$. pectoralis major et minor, vena saphena magna et parva; 
- the location or spatial relations, e.g. ligg. collateralia, lig. coracoacromiale, planum transpyloricum, trigonum femorale, epigastrium, cardia, regio hypochondriaca;

- the function, e.g. atlas, cisterna chyli, confluens sinuum, vesica urinaria, vesica biliaris seu fellea, funiculus spermaticus, $m$. sphincter et dilatator pupillae;

- the colour, e.g. ligamenta flava, linea alba, macula lutea, substantia nigra, nucleus ruber, and some other attributes of the structures of the human body. Terminologia Anatomica [5] has a complex and hierarchical structure that implies the natural relationships between the anatomical terms. The names are listed according to systemic, topographical, and alphabetical rules, which constitutes a logical system of organisation of terms and facilitates the use of this book in practice. The hierarchy is marked by the use of different fonts as well as varied shading of the panels in which the headings appear. It is noteworthy that the traditional Latin terms are associated with their English equivalents. Moreover, the special index of eponyms enables the reader to find the correct non-eponymous terms.

Every anatomical term used in TA has its identifying number (the TA code), which is very helpful, but there are several minor mistakes in this coding system. For example, the communicating branch of the vagus nerve with the glossopharyngeal nerve has the same TA code as the communicating branch of the glossopharyngeal nerve with the vagus nerve, i.e. A14.2.01.143 [5] (see page 136). Similarly, the anteromedial central branches of the anterior cerebral artery share their TA codes with the anteromedial central branches of the anterior communicating artery, i.e. A12.2.07.024 (see page 82). The code for the vestibule (vestibulum vaginae) should read "A09.2.01.11", and not "A09.2.01.12", because the latter is identical to the next entry in the list, while the former is missing (see page 66). Furthermore, the code A12.3.10.026 contains the following terms: "pubic vein; pubic branch (accessory obturator vein)", but these terms are not synonymous, and therefore the accessory obturator vein should receive its own number. Likewise, the TA code A12.2.01.202 designates both ligamentum arteriosum and ductus arteriosus.

\section{EXAMPLES OF TERMINOLOGICAL INACCURACIES FOUND IN THE ANATOMICAL AND SCIENTIFIC LITERATURE}

Although some anatomical textbooks seem impeccable with respect to anatomical terminology, the vast majority of otherwise extremely valuable sources usu- ally contain small departures (Table 1) from the terminology adopted by the FCAT [5]. Fortunately, such minor mistakes or inaccuracies do not usually lead to miscommunication as they do not change the meaning of the term. For example, if the carotid triangle is erroneously referred to as "the carotid artery triangle" [2], it is redundant but relatively harmless because of explicitness. Similarly, the common use of certain outdated, colloquial, or erroneous terms in the abovementioned textbooks, such as: ventriculus instead of gaster, fundus ventriculi instead of fundus gastricus, plexus solaris instead of plexus coeliacus, armpit instead of axilla, lower extremity instead of lower limb, odontoid process instead of dens axis, foramen cecum instead of foramen caecum, sulcus (pre)chiasmatis instead of sulcus prechiasmaticus, gyrus hippocampi instead of gyrus parahippocampalis, foramen processus transversi instead of foramen transversarium, facies pelvina (os sacrum) instead of facies pelvica, interdigital joints instead of interphalangeal joints, compages thoracis instead of cavea thoracis, fossa cranialis anterior instead of fossa cranii anterior, linea nuchae superior instead of linea nuchalis superior, fossa ischiorectalis instead of fossa ischioanalis, musculus pterygoideus externus (and internus) instead of musculus pterygoideus lateralis (and medialis), musculus obturator internus (and externus) instead of musculus obturatorius internus (and externus), fascia lumbalis instead of fascia thoracolumbalis, membrana tympani instead of membrana tympanica, and canalis hypoglossalis instead of canalis nervi hypoglossi, does not usually cause any ambiguity.

However, the widespread use of the Arabic numerals for determining the vertebrae, e.g. C1-7, $T(h) 1-12, \mathrm{~L} 1-5$, S1-5, instead of the Roman numerals can sporadically lead to confusion or misunderstanding since the Arabic numerals used after a capital letter should be confined to the names of the segments of the spinal cord and the spinal nerves [5]. Similarly, the term navicular bone should be used solely for one of the tarsal bones, and not for the scaphoid bone, since the former belongs to the bones of the foot, and the latter belongs to the bones of the wrist.

Curiously, almost all authors use the erroneous term processus mamillaris (vertebrae lumbales) instead of the proper term processus mammillaris (A02.2.04.004). Occasionally, the term processus costarius is used instead of the correct term processus costalis (costiformis). These small mistakes seem rather innocuous. However, it should be stressed that even a minor error that disrupts precise communication can cause a disturbance during 
Table 1. The comparison of erroneous or outdated terms from previous nomenclatures and valid terms along with pertinent identifying numbers used by the Federative Committee on Anatomical Terminology (FCAT) in Terminologia Anatomica (TA) [5]

\begin{tabular}{|c|c|c|}
\hline Erroneous or obsolete term & Preferred term & TA code \\
\hline annulus fibrosus & anulus fibrosus & A03.2.02.004 \\
\hline arteria anonyma & truncus brachiocephalicus & A12.2.04.004 \\
\hline arteria hypogastrica & arteria iliaca interna & A12.2.15.001 \\
\hline arteria mammaria interna & arteria thoracica interna & A12.2.08.029 \\
\hline C1-C7 (vertebrae) & $\mathrm{Cl}-\mathrm{CVII}$ & A02.2.02.001 \\
\hline canalis hypoglossalis & canalis nervi hypoglossi & A02.1.04.016 \\
\hline centrum tendineum perinei & corpus perineale/centrum perinei & A09.5.00.005 \\
\hline chorda uteroinguinalis & ligamentum teres uteri & A12.2.16.007 \\
\hline compages thoracis & cavea thoracis & A02.3.04.001 \\
\hline epipharynx/nasopharynx & pars nasalis pharyngis & A05.3.01.003 \\
\hline esophagus & oespophagus & A05.4.01.001 \\
\hline facies pelvina (os sacrum) & facies pelvica (os sacrum) & A02.2.05.009 \\
\hline fontanella & fonticulus & A02.1.00.027 \\
\hline foramen cecum & foramen caecum & A02.1.03.018 \\
\hline foramen processus transversi & foramen transversarium & A02.2.02.003 \\
\hline fossa cranialis anterior & fossa cranii anterior & A02.1.00.048 \\
\hline fossa cranialis media & fossa cranii media & A02.1.00.049 \\
\hline fossa cranialis posterior & fossa cranii posterior & A02.1.00.050 \\
\hline fossa ischiorectalis & fossa ischioanalis & A09.5.04.001 \\
\hline fornix ventriculi & fornix gastricus & A05.5.01.010 \\
\hline fundus ventriculi & fundus gastricus & A05.5.01.009 \\
\hline gyrus hippocampi & gyrus parahippocampalis & A14.1.09.234 \\
\hline hilus pulmonis & hilum pulmonis & A06.5.01.015 \\
\hline hilus renalis & hilum renale & A08.1.01.004 \\
\hline hilus splenicus (lienalis) & hilum splenicum (lienale) & A13.2.01.017 \\
\hline introitus vaginae & ostium vaginae & A09.2.01.015 \\
\hline laryngopharynx & pars laryngea pharyngis & A05.3.01.023 \\
\hline lien & splen/lien & A13.2.01.001 \\
\hline ligamentum annulare radii & ligamentum anulare radii & A03.5.09.007 \\
\hline ligamentum collaterale laterale & ligamentum collaterale fibulare & A03.6.08.011 \\
\hline ligamentum collaterale mediale & ligamentum collaterale tibiale & A03.6.08.012 \\
\hline linea nuchae suprema & linea nuchalis suprema & A02.1.04.024 \\
\hline linea nuchae superior & linea nuchalis superior & A02.1.04.025 \\
\hline linea nuchae inferior & linea nuchalis inferior & A02.1.04.026 \\
\hline membrana tympani & membrana tympanica & A15.3.01.052 \\
\hline musculus obturator externus & musculus obturatorius externus & A04.7.02.031 \\
\hline musculus obturator internus & musculus obturatorius internus & A04.7.02.012 \\
\hline musculus pterygoideus externus & musculus pterygoideus lateralis & A04.1.04.006 \\
\hline musculus pterygoideus internus & musculus pterygoideus medialis & A04.1.04.009 \\
\hline os naviculare (manus) & os scaphoideum & A02.4.08.003 \\
\hline plexus solaris & plexus coeliacus & A14.3.03.020 \\
\hline processus costarius (LI-LV) & processus costalis & A02.2.04.003 \\
\hline processus muscularis mandibulae & processus coronoideus mandibulae & A02.1.15.032 \\
\hline
\end{tabular}


Table 1. cont. The comparison of erroneous or outdated terms from previous nomenclatures and valid terms along with pertinent identifying numbers used by the Federative Committee on Anatomical Terminology (FCAT) in Terminologia Anatomica (TA) [5]

\begin{tabular}{lcc}
\hline Erroneous or obsolete term & Preferred term & TA code \\
\hline processus transversus (LI-LV) & processus costalis & $\mathrm{A} 02.2 .04 .003$ \\
processus mamillaris & processus mammillaris & $\mathrm{A} 02.2 .04 .004$ \\
sulcus chiasmatis & sulcus prechiasmaticus & $\mathrm{A} 02.1 .05 .005$ \\
sulcus prechiasmatis & sulcus prechiasmaticus & $\mathrm{A} 02.1 .05 .005$ \\
taenia anterior & taenia libera & $\mathrm{A} 05.7 .03 .016$ \\
vena anonyma & vena brachiocephalica & $\mathrm{A} 12.3 .04 .001$ \\
vena saphena & vena saphena magna & $\mathrm{A} 12.3 .11 .003$ \\
ventriculus & gaster & $\mathrm{A} 05.5 .01 .001$ \\
\hline
\end{tabular}

surgery, and may lead to some serious consequences, including patient's untimely demise. Therefore, it is important to use the recent version of the anatomical terminology during medical procedures. Furthermore, such terminology should not be revised too often because changes and amendments can disrupt communication between older and younger generations of physicians. As stated previously in the Introduction, the process of learning and remembering the anatomical terminology constitutes a daunting and formidable challenge to young and zestful students, not to mention senior medical staff, and therefore any major change to the anatomical terminology is inadvisable.

\section{EXAMPLES OF CONFUSING AND ERRONEOUS ANATOMICAL TERMS USED IN CLINICAL PRACTICE}

In anatomy and other medical fields, eponyms are names that commemorate (often erroneously) a famous person who described a given structure, procedure, condition or disorder, although sometimes it is a fictitious character like Achilles, and they are believed to be a useful reflection of the history of medicine, hence their historical significance. There is no doubt that they enliven medical study and practice. On the other hand, they constitute the system that is inconvenient and obscure, does not lend any insight into the location and definition of structures, poses serious difficulties for students, and also can lead to miscommunication or even mistakes in the scientific literature [1, 3, 4, 16, 28]. Therefore, eponymous terms should be used sparingly, especially in the process of teaching anatomy to medical students. In fact, many eponyms are still commonly used in clinical practice (Table 2), and contemporary medicine is replete with them.

It is noteworthy that some medical errors may result from the use of mental shortcuts in anatomical termi- nology. For example, many clinicians, and surgeons in particular, refer to vena saphena magna as "saphena". Since the superficial group of veins draining the lower limb forms two major channels, i.e. the great saphenous vein (vena saphena magna) and the small saphenous vein (vena saphena parva), which originate from the medial and lateral sides, respectively, of a dorsal venous arch in the foot, it is easy to see that such imprecise and vernacular expression can lead to miscommunication. It is theoretically possible that a diagnosis of "varicose saphena" in a patient with varicosities of the small saphenous vein would be understood by surgeons as the varicosities of the great saphenous vein since the varicosities of the small saphenous vein are rarely treated by operation. Thus, in surgery the term "saphena" means vena saphena magna, and is a misnomer when referring to vena saphena parva. Moreover, many clinicians refer to the perforating veins (venae perforantes, A12.3.11.007) as "perforators" or even "Boyd's, Dodd's or Cockett's perforators", which is another example of clinical jargon.

Similarly, when someone refers to fibular collateral ligament ( $\mathrm{FCL}$ ) as lateral collateral ligament ( $\mathrm{LCL})$, as many clinicians do, there is a greater chance of likelihood of confusion because FCL belongs to the ligament of the knee joint, and extends from the lateral epicondyle of the femur to the head of the fibula, whereas ligamentum collaterale laterale (lateral ligament) belongs to the ligaments of the ankle joint and consists of three ligaments: the anterior talofibular, the calcaneofibular, and the posterior talofibular ligaments. Moreover, numerous anatomists and researchers use the term lateral collateral ligament as the equivalent of ligamentum collaterale laterale instead of lateral ligament [7], hence the need for extreme caution. In veterinary anatomy, however, $\mathrm{LCL}$ is an equivalent of FCL [24]. 
Table 2. The comparison of anatomical terms that are commonly used in clinical practice (eponyms) and pertinent terms used in Terminologia Anatomica (TA) [5]

\begin{tabular}{|c|c|c|}
\hline Term used in clinical practice & Equivalent term used in TA & TA code \\
\hline anulus Waldeyer & anulus lymphoideus pharyngis & A13.2.02.001 \\
\hline aqueductus Sylvii & aqueductus mesencephali (cerebri) & A14.1.06.501 \\
\hline arcada Riolani & a. marginalis coli (a. juxtacolica) & A12.2.12.068 \\
\hline arteria Adamkiewicz & a. radicularis anterior & A12.2.11.015 \\
\hline arteria Heubneri & a. striata medialis distalis & A12.2.07.034 \\
\hline articulatio Choparti & articulatio tarsi transversa & A03.6.10.201 \\
\hline articulatio Lisfranci & articulationes tarsometatarales & A03.6.10.601 \\
\hline canalis Alcock & canalis pudendalis & A09.5.04.003 \\
\hline cavum Douglas & excavatio rectouterina (\&) & A10.1.02.512 \\
\hline cavum Meckel & cavum trigeminale & A14.1.01.108 \\
\hline circulus venosus Ridleyi & - & - \\
\hline circulus arteriosus Willisi & circulus arteriosus cerebri & A12.2.07.080 \\
\hline ductus Bartholini & ductus sublingualis major & A05.1.02.009 \\
\hline ductus Botalli & ductus arteriosus (lig. arteriosum) & $\mathrm{A} 12.2 .01 .202$ \\
\hline ductus Rivini & ductus sublinguales minores & A05.1.02.010 \\
\hline ductus Santorini & ductus pancreaticus accessorius & A05.9.01.017 \\
\hline ductus Stenoni & ductus parotideus & A05.1.02.007 \\
\hline ductus Whartoni & ductus submandibularis & A05.1.02.012 \\
\hline ductus Wirsungi & ductus pancreaticus & A05.9.01.015 \\
\hline fascia Camperi & panniculus adiposus & A04.5.02.024 \\
\hline fascia Scarpae & stratum membranosum & A04.5.02.022 \\
\hline fasciculus Paladino-His & fasciculus atrioventricularis & A12.1.06.005 \\
\hline foramen Magendi & apertura mediana ventriculi quarti & A14.1.05.722 \\
\hline foramen Monroi & foramen interventriculare & A14.1.08.411 \\
\hline foramina Luschka & apertura lateralis & A14.1.05.718 \\
\hline ganglion Gasser & ganglion trigeminale & A14.2.01.014 \\
\hline ligamentum Treitzi & musculus supensorius duodeni & A05.6.02.011 \\
\hline ligamentum Cooper & ligamentum pectineum & A04.5.01.011 \\
\hline ligamentum Poupart & ligamentum inquinale & A04.5.01.009 \\
\hline ligamentum Vesalius & ligamentum inquinale & A04.5.01.009 \\
\hline ligamentum Walther & lig. tibiofibulare anterius & A03.6.05.003 \\
\hline nodus Aschoff-Tawara & nodus atrioventricularis & A12.1.06.004 \\
\hline nodus Keith-Flack & nodus sinuatrialis & A12.1.06.003 \\
\hline papilla Brunneri & papilla duodeni minor & A05.6.02.016 \\
\hline papilla Vateri & papilla duodeni major & A05.6.02.015 \\
\hline plexus (area) Kiesselbach & - & - \\
\hline plica Douglas & plica rectouterina (\&) & A10.1.02.511 \\
\hline plica Kohlrausch & plica transversa recti (media) & A05.7.04.007 \\
\hline plica Traves & plica ileocaecalis & A10.1.02.421 \\
\hline pons Varoli & pons & A14.1.03.010 \\
\hline recessus Huschke & recessus paraduodenalis & A10.1.02.415 \\
\hline recessus Rosenmüller & recessus pahryngeus & A05.3.01.017 \\
\hline torcular Herophilus & confluens sinuum & $\mathrm{A} 12.3 .05 .103$ \\
\hline
\end{tabular}


Table 2. cont. The comparison of anatomical terms that are commonly used in clinical practice (eponyms) and pertinent terms used in Terminologia Anatomica (TA) [5]

\begin{tabular}{lcc}
\hline Term used in clinical practice & Equivalent term used in TA & TA code \\
\hline valva bicuspidalis & valva mitralis & $\mathrm{A} 12.1 .04 .003$ \\
valva ileoc(a)ecalis Bauhini & papilla ilealis & $\mathrm{A} 05.7 .02 .002$ \\
valva Heister & plica spiralis & $\mathrm{A} 05.8 .02 .012$ \\
valva Tulp & papilla ilealis & $\mathrm{A} 05.7 .02 .002$ \\
valvula Petit & plica spiralis & $\mathrm{A} 05.8 .02 .012$ \\
vena Galeni & vena magna cerebri & $\mathrm{A} 12.3 .06 .027$ \\
vena Labbé (vein of Labbé) & vena anastomotica inferior & $\mathrm{A} 12.2 .06 .010$ \\
vena Latarget & vena prepylorica & $\mathrm{A} 12.3 .12 .017$ \\
vena Marschall & vena obliqua atrii sinistri & $\mathrm{A} 12.3 .01 .007$ \\
vena Mayo & vena prepylorica & $\mathrm{A} 12.3 .12 .017$ \\
vena Rosenthalii & vena basalis & $\mathrm{A} 12.3 .06 .018$ \\
vena Trolardi & vena anastomotica superior & $\mathrm{A} 12.2 .06 .012$ \\
venae Thebesii & venae cardiacae minimae & $\mathrm{A} 12.3 .01 .013$ \\
\hline
\end{tabular}

There are also little mistakes that are extremely dangerous because they completely change the meaning of the term. For example, mistakenly changing malleus to malleolus, changes the name of a middle-ear bone to the name of a bony prominence on each side of the ankle. Likewise, if trapezius is misspelled as trapezium, the name of the superficial muscle of the back changes into the name of a carpal bone that lies in the wrist. Another mistake such as misspelling ileum as ilium changes the name of the final section of the small intestine to the name of the hip bone. Interestingly, the term hip bone (os coxae) itself is often referred to as either the innominate bone, which is an obsolete term and should be avoided, or the pelvic (or coxal) bone, which are both correct [5].

Other such mistakes and inaccuracies are usually less harmful. For example, plexus hypogastricus inferior is often called plexus pelvicus. The latter term correctly describes the location of the structure but can be confused with the rectal venous plexus (plexus venosus rectalis), since the autonomic plexuses are usually less important to surgeons than blood vessels.

In clinical anatomy, the "common femoral artery" gives off two branches, i.e. the "superficial" and the "deep femoral artery". In topographic anatomy, the femoral artery as the continuation of the external iliac artery begins under the inguinal ligament to enter the femoral triangle, where it lies superficially covered by the fascia lata and the sartorius muscle, and it continues down in the adductor canal. Through the adductor ca- nal, it reaches the popliteal fossa, where it changes its name into the popliteal artery. The femoral artery gives off a cluster of small branches, including the superficial epigastric artery, superficial circumflex iliac artery, superficial external pudendal artery, and deep external pudendal artery, and the largest branch of the femoral artery, i.e. the deep artery of the thigh (arteria profunda femoris), which originates from the lateral side of the femoral artery in the femoral triangle. Thus, there is no "deep" or "superficial" femoral artery. The former term refers to the deep artery of the thigh, and the latter designates the superficial continuation of the femoral artery on its way to the popliteal fossa.

\section{CONCLUSIONS}

Ambiguity and miscommunication can cause serious problems during the process of diagnosis and treatment. Miscommunication may result from the use of ambiguous, erroneous, and obsolete anatomical terms, and many such terms are still widely used by clinicians. For example, the system of eponyms, which is very inconvenient and obscure, ought not to be used anymore, especially when teaching anatomy to medical students. The anatomical terminology and nomenclature should be used correctly in both theoretical medicine and clinical practice. In our opinion, it is important to use the recent version of the anatomical terminology during medical procedures and in scientific writing. Since the process of learning, remembering, and understanding the anatomical terminology constitutes a difficult challenge, the terminology should 
not be changed too often. Accordingly, any major change to the recent version of the anatomical terminology would do more harm than good. Nevertheless, some minor corrections and extensions with respect to small and variant structures, which can be important from a scientific point of view, are very welcome.

\section{REFERENCES}

1. Aresti N, Ramachandran M. Nonoriginal Malappropriate Eponymous Nomenclature: examples relevant to paediatric orthopaedics. J Pediatr Orthop B. 2012; 21(6): 606-610, doi: 10.1097/BPB.0b013e328356f9a5, indexed in Pubmed: 22814740.

2. Chmielewski P, Borysławski K, Chmielowiec K, et al. Longitudinal and cross-sectional changes with age in selected anthropometric and physiological traits in hospitalized adults: an insight from the Polish Longitudinal Study of Aging (PLSA). Anthropol Rev. 2015; 78(3): 317-336, doi: 10.1515/anre-2015-0025.

3. Conti AA. Calling the heart by name: distinguished eponyms in the history of cardiac anatomy. Heart Surg Forum. 2011; 14(3): E183-E187, doi:10.1532/HSF98.20101047, indexed in Pubmed: 21676685.

4. DiPoce J, Jimenez G, Weintraub J. Historical perspective: eponyms of vascular radiology. Radiographics. 2014; 34(4): 1120-1140, doi:10.1148/rg.344130125, indexed in Pubmed: 25019445.

5. FCAT Terminologia Anatomica. International Anatomical Terminology. 2nd edition. Georg Thieme Verlag, Stuttgart. 2011.

6. Gielecki J, Zurada A, Osman N. Terminologia anatomica in the past and the future from perspective of 110th anniversary of Polish Anatomical Terminology. Folia Morphol. 2008; 67(2): 87-97, indexed in Pubmed: 18521806.

7. Golanó P, Vega J, de Leeuw PAJ, et al. Anatomy of the ankle ligaments: a pictorial essay. Knee Surg Sports Traumatol Arthrosc. 2010; 18(5): 557-569, doi: 10.1007/s00167010-1100-x, indexed in Pubmed: 20309522.

8. Hill M, Davis M. Local control of microvascular perfusion. Morgan \& Claypool Life Sciences, New York. 2013.

9. Hirsch BE. Does the Terminologia Anatomica really matter? Clin Anat. 2011; 24(4): 503-504, doi: 10.1002/ca.21140, indexed in Pubmed: 21509816.

10. Kachlik D, Baca V, Bozdechova I, et al. Anatomical terminology and nomenclature: past, present and highlights. Surg Radiol Anat. 2008; 30(6): 459-466, doi: 10.1007/ s00276-008-0357-y, indexed in Pubmed: 18488135.

11. Kachlík D, Bozdechová I, Cech P, et al. [Ten years after the latest revision International Anatomical Terminology]. Cas Lek Cesk. 2008; 147(5): 287-294, indexed in Pubmed: 18630187.

12. Kachlik D, Bozdechova I, Cech P, et al. Mistakes in the usage of anatomical terminology in clinical practice. Biomed Pap Med Fac Univ Palacky Olomouc Czech Repub. 2009; 153(2): 157-161, indexed in Pubmed: 19771143.

13. Kachlik D, Musil V, Baca V. Terminologia Anatomica after 17 years: inconsistencies, mistakes and new proposals. Ann Anat. 2015; 201: 8-16, doi:10.1016/j.aanat.2015.04.006, indexed in Pubmed: 26094127.

14. Kachlik D, Musil V, Baca V. Contribution to the anatomical nomenclature concerning general anatomy and anatomical variations. Surg Radiol Anat. 2016; 38(7): 757-765, doi: 10.1007/s00276-016-1627-8, indexed in Pubmed: 26946463.

15. Kumka M, Bonar J. Fascia: a morphological description and classification system based on a literature review. J Can Chiropr Assoc. 2012; 56(3): 179-191, indexed in Pubmed: 22997468.

16. Kutia SA. Eponyms in biliary tree. Eksp Klin Gastroenterol. 2014(10): 106-110, indexed in Pubmed: 25911940.

17. Martin BD, Thorpe $D$, Barnes $R$, et al. Frequency in usage of FCAT-approved anatomical terms by North American anatomists. Anat Sci Educ. 2009; 2(3): 94-106, doi: 10.1002/ ase.83, indexed in Pubmed: 19459207.

18. Martin B, Thorpe D, DeLuna $V$, et al. Frequency in Usage ofTerminologia AnatomicaTerms by Clinical Anatomists. J Biomed Edu. 2014; 2014: 1-9, doi: 10.1155/2014/950898.

19. Martin BD, Thorpe D, Merenda V, et al. Contrast in usage of FCAT-approved anatomical terminology between members of two anatomy associations in North America. Anat Sci Educ. 2010; 3(1): 25-32, doi: 10.1002/ase.114, indexed in Pubmed: 19890984.

20. Matusz P. Misleading Latin/English equivalents for some liver terms in Terminologia Anatomica. Anat Sci Educ. 2010; 3(3): 156-157, doi: 10.1002/ase.133, indexed in Pubmed: 20186839.

21. Mirilas $P$, Skandalakis JE. Benign anatomical mistakes: the correct anatomical term for the recurrent laryngeal nerve. Am Surg. 2002; 68(1): 95-97, indexed in Pubmed: 12467328.

22. Pawlina W, Drake R. Moving forward with Terminologia Anatomica. Anat Sci Educ. 2009; 2(3): 93, doi: 10.1002/ ase.89, indexed in Pubmed: 19496153.

23. Sakai T. Historical evolution of anatomical terminology from ancient to modern. Anat Sci Int. 2007; 82(2): 65-81, doi: 10.1111/j.1447-073X.2007.00180.x, indexed in Pubmed: 17585563.

24. Schaller O. Illustrated veterinary anatomical nomenclature. Enke Verlag, Stuttgart. 2007

25. Schleip $R$, Jäger $H$, Klingler W. What is 'fascia'? A review of different nomenclatures. J Bodyw Mov Ther. 2012; 16(4): 496-502, doi:10.1016/j.jbmt.2012.08.001, indexed in Pubmed: 23036881.

26. Urbanowicz Z. Mała encyklopedia anatomii człowieka. Czelej, Lublin. 2003.

27. Vogl AW. Awareness of and access to a unified terminology by anatomists. Anat Sci Educ. 2009; 2(3): 139-140, doi: 10.1002/ase.85, indexed in Pubmed: 19496162.

28. Waseem M, Khan M, Hussain N, et al. Eponyms: errors in clinical practice and scientific writing. Acta Orthop Belg. 2005; 71(1): 1-8, indexed in Pubmed: 15792200.

29. Weber JC. Shearer's manual of human dissection. McGrawHill, New York 1999.

30. Wendell-Smith C. Terminological desiderata. Clin Anat. 2003; 16(1): 98-103, doi: 10.1002/ca.10131, indexed in Pubmed: 12486743 .

31. Whitmore I. Terminologia anatomica: new terminology for the new anatomist. Anat Rec. 1999; 257(2): 50-53, indexed in Pubmed: 10321431.

32. Yabuki Y. Clinical anatomy of the subserous layer: An amalgamation of gross and clinical anatomy. Clin Anat. 2016; 29(4): 508-515, doi:10.1002/ca.22579, indexed in Pubmed: 26621479. 